\title{
Friction and Wear of Silicon Carbide at Elevated Temperatures
}

\author{
Hanning XIAO and Tetsuya SENDA* \\ Hunan University, Changsha, Hunan 410082, China \\ *Ship Research Institute, Ministry of Transport, 6-38-1, Shinkawa, Mitaka-shi, Tokyo 181 \\ 炭化ケイ素の高温摩擦摩耗特性 \\ 肖 漢寧・千田哲也* \\ 湖南大学, 中国湖南省長沙 410082 \\ *運輸省船舶技術研究所, 181 東京都三鷹市新川 6-38-1
}

\begin{abstract}
Friction and wear tests of sintered $\alpha-\mathrm{SiC}$ were conducted from room temperature to $1200^{\circ} \mathrm{C}$ both in air and vacuum. The coefficient of friction was larger in air than that in vacuum but was almost independent of the temperature. The specific wear loss generally increased with an increase of temperature. However, a substantial decrease in wear loss was observed at the highest temperature for lower contact pressure tests where a thick layer of small particles was formed on the friction surface. Silicon oxide was identified in wear debris particles particularly collected from high-temperature tests. It suggests that oxidation, which is accelerated at high temperatures, generally promotes material removal, resulting in a higher wear loss. However, the wear loss could decrease when oxide-containing particles form a thick surface layer.
\end{abstract}

[Received April 16, 1997; Accepted June 6, 1997]

Key-words : Silicon carbide, Tribology, Friction, Wear, High temperature, Oxidation, Microfracture

1. Introduction

Silicon carbide ( $\mathrm{SiC}$ ) has high hardness and excellent chemical and mechanical properties at elevated temperatures and is therefore expected to be a candidate for tribological applications in severe and/or high-temperature environments. Potential applications include industrial nozzles, pump seals and heat engine parts. ${ }^{1)}$ Further engineering applications as a corrosion or abrasion resistant material at high temperatures are also promising. $\left.{ }^{2}\right)$

Fundamental understanding of the friction and wear mechanisms and the effect of environmental conditions such as temperature and atmosphere is essential requirement for the selection or design of a ceramic material for practical applications. Several researchers have addressed tribological characteristics of $\mathrm{SiC} / \mathrm{SiC}$ pairs ${ }^{3)-19)}$ or $\mathrm{SiC} /$ other ceramics pairs. ${ }^{20), 21)}$ Tribochemical reactions, including oxidation and decomposition of $\mathrm{SiC}$, become evident at high temperatures and may have a critical effect on the tribological behaviors. It has been reported that oxidation accelerates material removal at the friction surface, ${ }^{6), 8)}$ while it improves wear resistance for some particular cases. ${ }^{6,7)}$ Decomposition of SiC usually occurs in inert or vacuum environment. Graphite layer of the decomposed carbon acts as a solid self-lubricant between the contact surfaces of SiC. ${ }^{9)}$ Most of the experimental studies on the tribology of $\mathrm{SiC}$ were conducted at ambient or moderate temperatures. Although several studies have been reported for high temperature tribology,5)-10) available results on the effect of temperature and atmosphere are still limited.

In the present study, a series of friction and wear tests were conducted in a plate-on-plate type test rig using a commercially available SiC ceramics. Detailed analyses were conducted for wear surfaces and debris particles. Results are compared with those in previous studies. Oxidation effects on the friction and wear mechanism are discussed mainly for two different wear modes observed at high temperatures.

2. Experimental procedures

The material used was a sintered silicon carbide $(\alpha-\mathrm{SiC}$, Nikkato, SiC-11) of 98 mass\% purity with a density of 3.1 $\times 10^{-3} \mathrm{~kg} / \mathrm{m}^{3}$. Wear tests of the plate-on-plate type were conducted with a dry friction test rig using a couple consisting of the same material. ${ }^{22), 23)}$ The specimen geometry is illustrated in Fig. 1. The apparent contact area was annularshaped with inner and outer diameters of 12 and $22 \mathrm{~mm}$, respectively. The specimens were ultrasonically cleaned in acetone for $5 \mathrm{~min}$ before and after test. The main portion of the test rig is schematically illustrated in Fig. 2. Each specimen was mounted in a superalloy (Hastelloy X) holder. The ring specimen was rotated on the plate specimen under a constant load provided by a servo-controlled pneumatic cylinder. The specimen holders were heated by high-frequency induction coils to the required temperature. For the tests in the vacuum condition, the sealed chamber, enclosing the test section, was evacuated with a rotary vacuum pump to the residual air pressure of 7-8 $\mathrm{Pa}$ at room temperature or $10-12 \mathrm{~Pa}$ at $1000^{\circ} \mathrm{C}$.

Coefficient of friction was measured at room temperature and from $200^{\circ} \mathrm{C}$ to $1200^{\circ} \mathrm{C}$ with an interval of $200^{\circ} \mathrm{C}$ under a constant sliding speed of $0.2 \mathrm{~m} / \mathrm{s}$. The contact pressure was provided as 0.4 and $1.2 \mathrm{MPa}$ in step at each temperature. A single pair of specimens was used for all the conditions in each environment.

The wear tests were usually conducted for a sliding distance of $500 \mathrm{~m}$ under constant conditions of temperature,

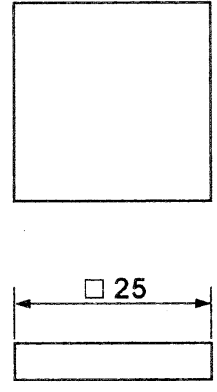

(A)
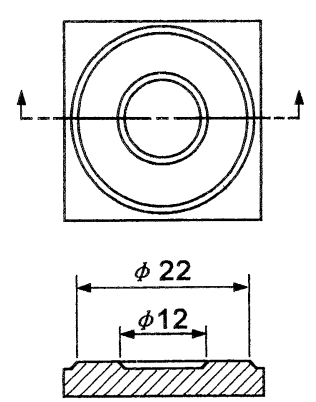

(B)
Fig. 1. Specimen geometry: (A) plate specimen and (B) ring specimen. 


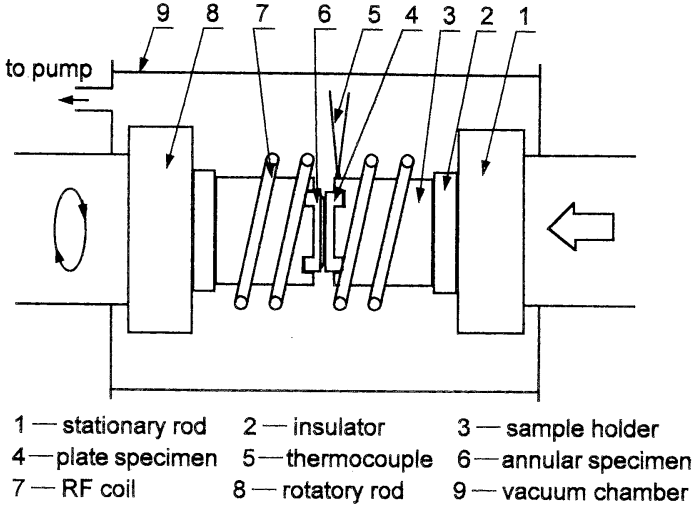

Fig. 2. Schematic of the main portion of the friction and wear test rig.

contact pressure ( 0.2 or $0.4 \mathrm{MPa}$ ) and sliding speed (mainly $0.2 \mathrm{~m} / \mathrm{s}$ ). The wear loss was measured as a change in mass of the specimens before and after test. Wear volume was calculated as the mass loss divided by the apparent density and then specific wear loss was determined as the wear volume divided by applied load and sliding distance in a dimension of $\mathrm{mm}^{3} /(\mathrm{N} \cdot \mathrm{m})$. It was given as an average of the values of the plate and ring specimens for each condition. The wear surfaces were observed by scanning electron microscope (SEM). Cross sectional observations by SEM were also conducted on the samples fractured perpendicular to the wear surface. Transmission electron microscopy (TEM), X-ray diffractometry (XRD) and X-ray photoelec-

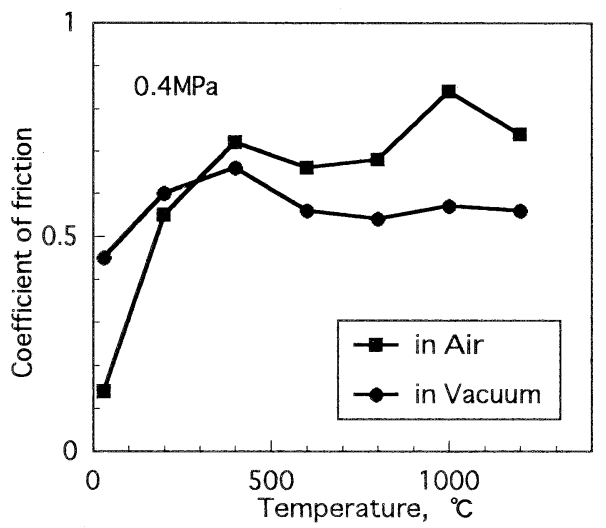

(A)

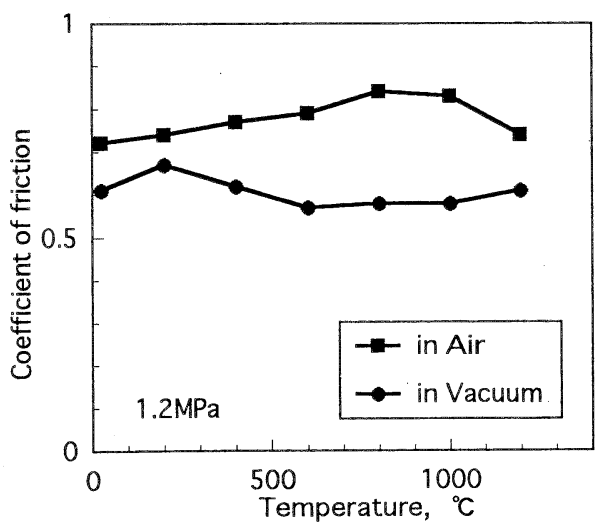

(B)

Fig. 3. Coefficient of friction at various temperatures: (A) under contact pressure of $0.4 \mathrm{MPa}$ and (B) $1.2 \mathrm{MPa}$. tron spectroscopy (XPS) were performed on the debris particles. Cross sectional region of the vicinity of the wear surface was analyzed with an electron-probe microanalyzer (EPMA).

\section{Results and discussion}

Figure 3 shows relationship between the coefficient of friction and temperature. The coefficient of friction varied between 0.5 and 0.8 except for a few particular cases. In general, the coefficient of friction in vacuum was smaller than that in air. Under the contact pressure of $1.2 \mathrm{MPa}$ the coefficient of friction was nearly constant from room temperature to $1200^{\circ} \mathrm{C}$. In air, the coefficient of friction was very low at room temperature when the applied load was $0.4 \mathrm{MPa}$. In ambient atmosphere, absorbed gas or humidity often promotes lubrication effects by some tribochemical reaction products when the applied load is not so high as severe wear taking place. Although it has been reported that graphite forms by decomposition of $\mathrm{SiC}$ resulting in a reduced coefficient of friction, such concentration of carbon was not detected in this study. Graphite would be more readily present on the wear surface in vacuum. However, no significant decrease in coefficient of friction has been observed in vacuum.

The specific wear loss at various temperatures is shown in Fig. 4. It is in an order of $10^{-5} \mathrm{~mm}^{3} /(\mathrm{N} \cdot \mathrm{m})$, comparable to other ceramics including $\mathrm{Al}_{2} \mathrm{O}_{3}$ and $\mathrm{TiB}_{2}{ }^{22), 24)}$ For the

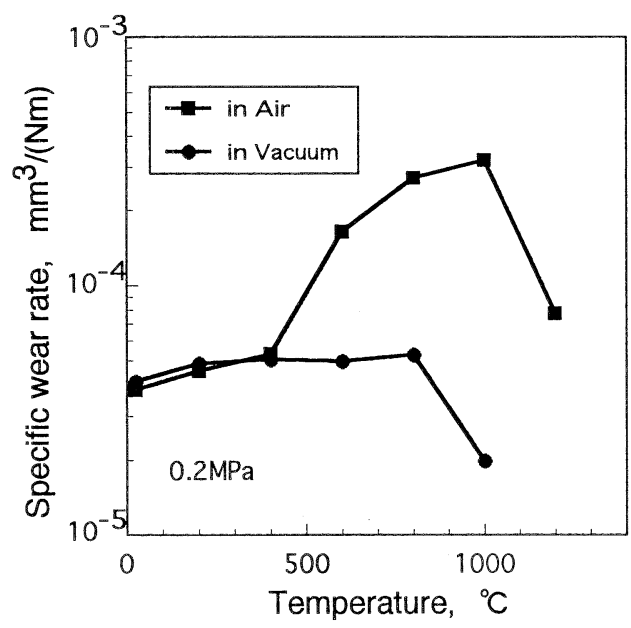

(A)

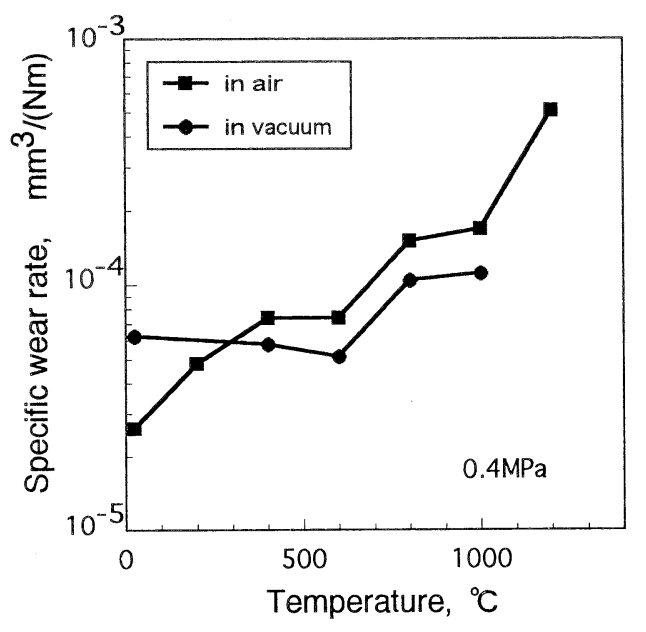

(B)

Fig. 4. Specific wear loss at various temperatures: (A) under contact pressure of $0.2 \mathrm{MPa}$ and (B) $0.4 \mathrm{MPa}$. 


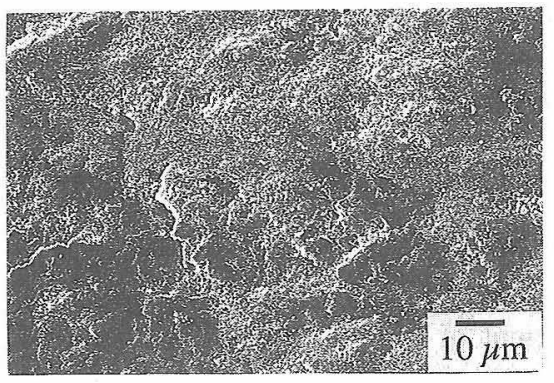

(A)

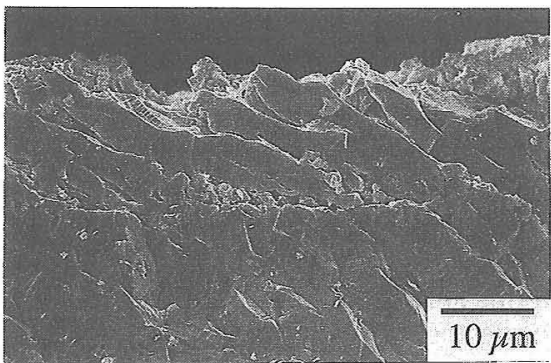

(D)

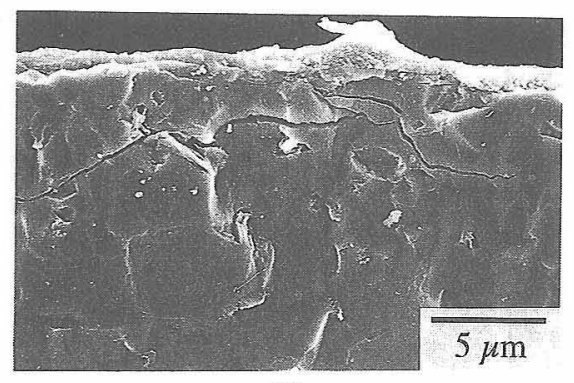

(B)

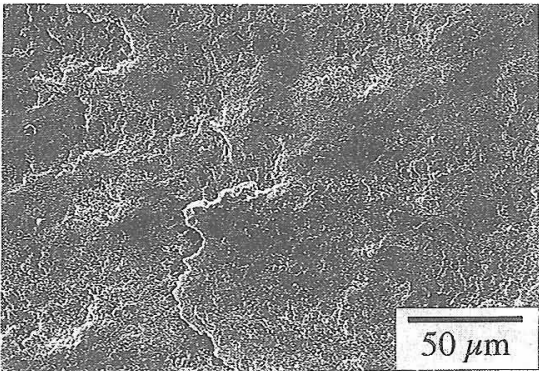

(E)

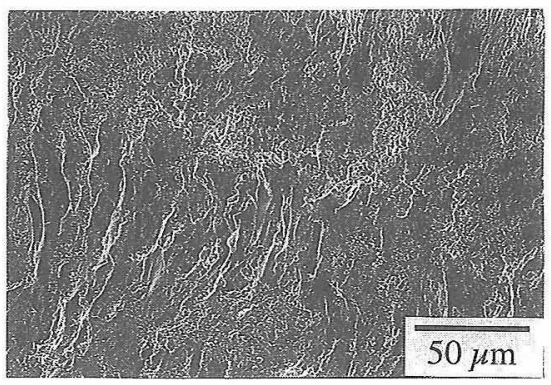

(C)

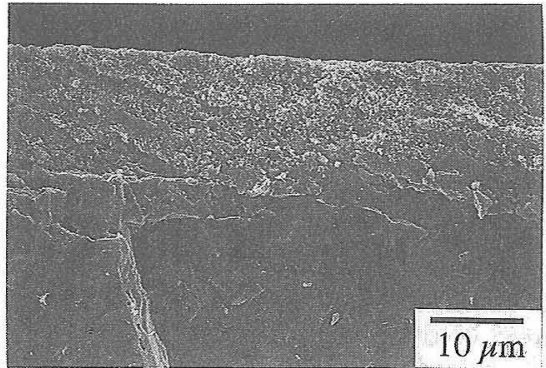

(F)

Fig. 5. SEM micrographs of the wear surface tested in air:

(A) plan view at room temperature under $0.4 \mathrm{MPa}$, (B) its cross section, (C) plan view at $1200^{\circ} \mathrm{C}$ under $0.4 \mathrm{MPa}$, (D) its cross section, (E) plan view at $1200^{\circ} \mathrm{C}$ under $0.2 \mathrm{MPa}$ and $(\mathrm{F})$ its cross section.

contact pressure of $0.2 \mathrm{MPa}$ specific wear loss increased significantly above $400^{\circ} \mathrm{C}$ but decreased at $1200^{\circ} \mathrm{C}$ in air. In vacuum, the specific wear loss exhibited a nearly constant value from room temperature to $800^{\circ} \mathrm{C}$, and then decreased at $1000^{\circ} \mathrm{C}$. When the contact pressure increased to 0.4 $\mathrm{MPa}$, the wear loss continuously increased above $800^{\circ} \mathrm{C}$. The general tendency is that specific wear loss increases with an increase of temperature, which is consistent with the results previously reported by Woydt and Habig, ${ }^{6)}$ Wang et $a .^{8)}$ and Mizutani et al. ${ }^{9)}$ However, there are two exceptions against this general tendency; namely $0.2 \mathrm{MPa}$ at $1000^{\circ} \mathrm{C}$ in vacuum and $0.2 \mathrm{MPa}$ at $1200^{\circ} \mathrm{C}$ in air.

Figure 5 shows micrographs of the wear surface regions in air. At room temperature, the wear surface was covered by fine particles of debris as shown in Fig. 5(A). Transgranular cracks parallel to the wear surface were often observed in cross-sectional views as shown in Fig. 5(B), suggesting that brittle microfracture is the dominant materialremoval mechanism. At $1200^{\circ} \mathrm{C}$, the surface morphology was dependent on the contact pressure, corresponding to the difference in the wear loss. Figures 5(C) and 5(D) reveal that numerous intergranular cracks were developed to the depth of approximately $10 \mu \mathrm{m}$ in the surface under the contact pressure of $0.4 \mathrm{MPa}$ where the wear was in the severer mode. In contrast, a thick surface layer of fine particles was observed under $0.2 \mathrm{MPa}$ where the wear loss significantly decreased, as shown in Figs. 5(E) and 5(F).

In vacuum, similar difference in wear surface morphology was observed at $1000^{\circ} \mathrm{C}$ as shown in Fig. 6 . For a contact pressure of $0.2 \mathrm{MPa}$, fine particles covered the wear surface and a very thin glassy layer without visible microcracking was formed in the cross sectional view. Although similar surface layer of fine particles was observed on the wear surface under a contact pressure of $0.4 \mathrm{MPa}$, delamination of the surface layer from the original bulk was readily observed. It should be noted that a thick layer consisting of small particles is always observed in the surface of the specimens in association with reduced wear loss at high temperatures.

XRD patterns of debris collected from the wear tests are

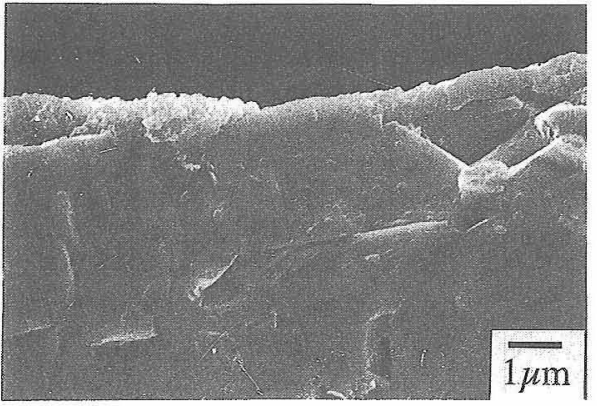

(A)

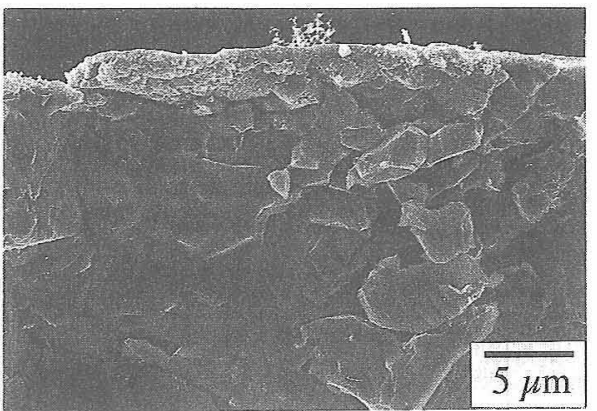

(B)

Fig. 6. Cross sectional view of the wear surface tested at $1000^{\circ} \mathrm{C}$ in vacuum: (A) under $0.2 \mathrm{MPa}$ and (D) $0.4 \mathrm{MPa}$.

summarized in Fig. 7 in comparison with the original bulk material in which only $\alpha$-SiC phase was identified. Diffraction patterns of wear debris exhibited a few broad peaks both in air and in vacuum. Silicon oxide, probably in amorphous state, was present when tested in air, especially at $600^{\circ} \mathrm{C}$ and above, while it was not clearly observed in vacuum. TEM observations of debris are shown in Fig. 8 . The debris particles were in an order of $0.1 \mu \mathrm{m}$ in size. Electron diffraction pattern of the core region of a debris particle, as shown in Fig. 8(A), was in agreement with 6H-SiC crystal 


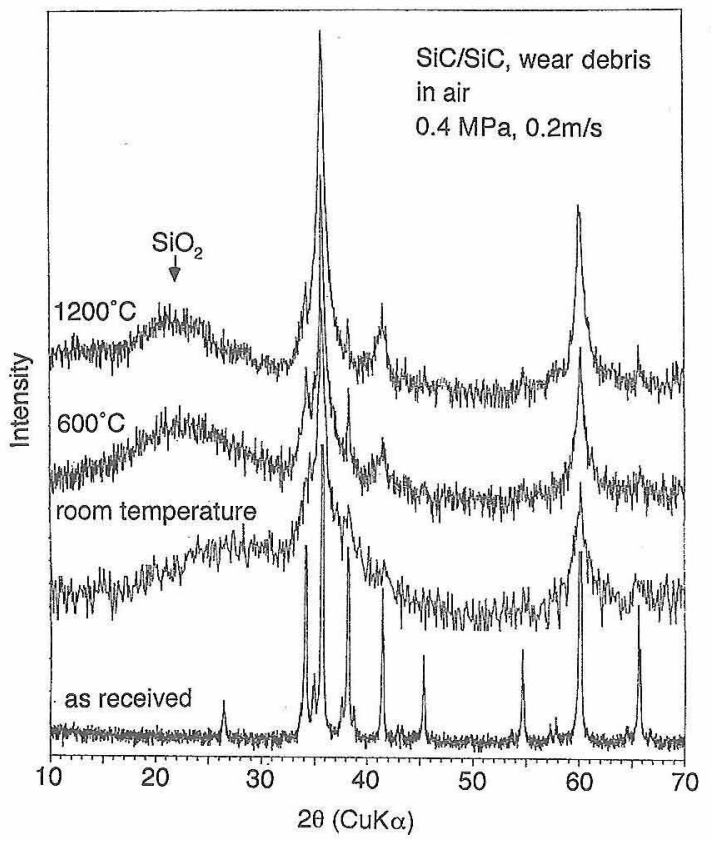

(A)

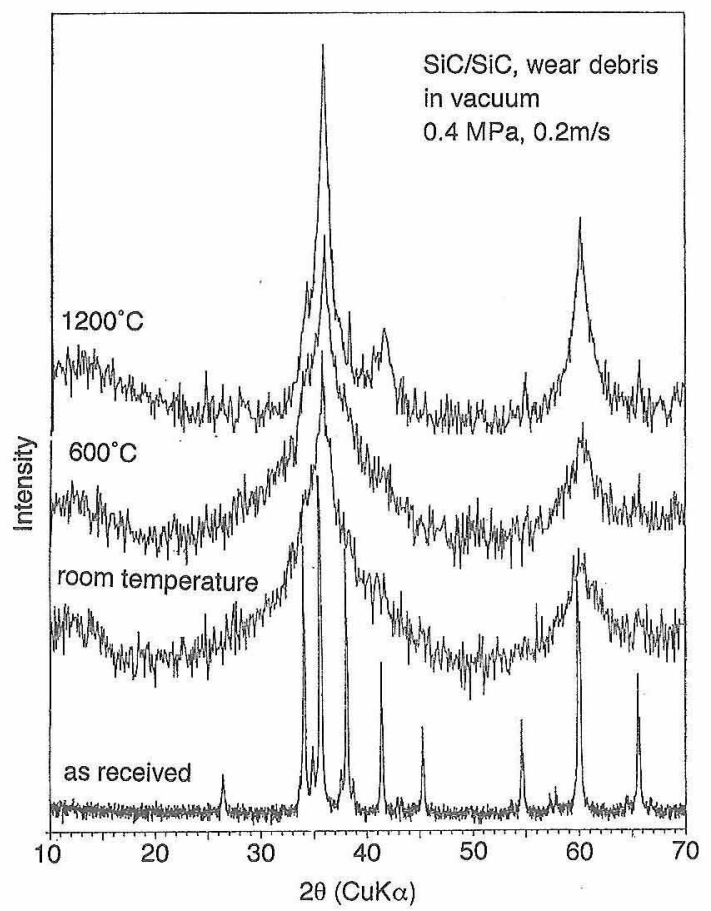

(B)

Fig. 7. XRD patterns of debris collected from the tests at various temperatures: (A) in air and (B) in vacuum.

$(\alpha-\mathrm{SiC})$. However, diffraction pattern from a surface region of the particle as shown in Fig. 8(B) exhibited amorphous features. Results of the XPS analyses are summarized in Fig. 9. Only $\mathrm{SiC}$ bond $(100.5 \mathrm{eV})$ was observed for the surface of the bulk sample before the wear test (Fig. 9(A)). However, debris particles from the wear tests at $600^{\circ} \mathrm{C}$ exhibited both $\mathrm{SiC}$ and $\mathrm{SiO}_{2}(103.5 \mathrm{eV}$ ) bondings (Fig. 9(B)).

A reasonable interpretation of these analyses is as follows: Debris particles are partially oxidized and consist of very fine $\mathrm{SiC}$ crystalline in the core region and $\mathrm{SiO}_{2}$ amorphous coatings in the surface. The SiC crystallite size is very small and therefore XRD peaks are very broad. In vacuum, oxide formation was observed by XPS (Fig. 9(C)),

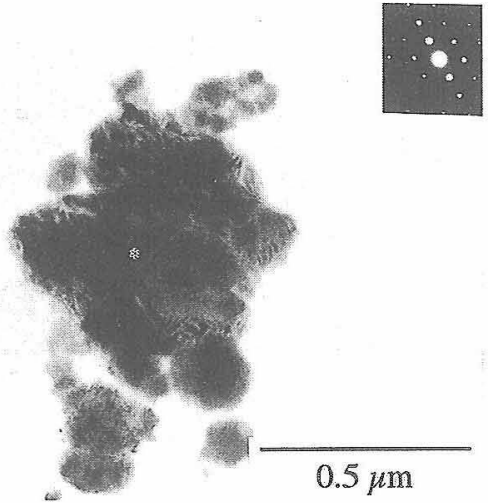

(A)

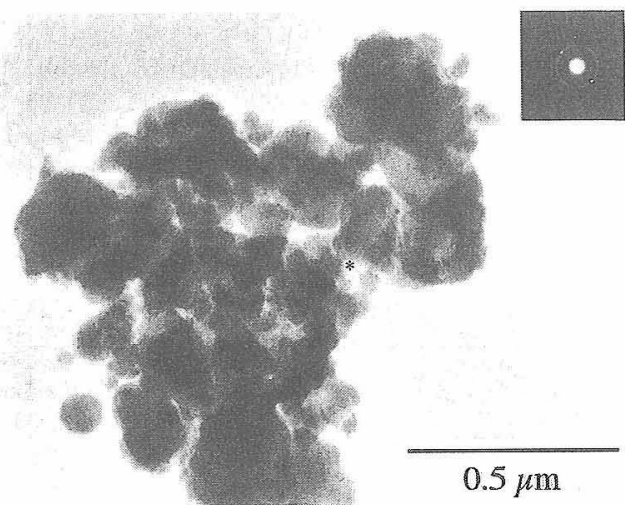

(B)

Fig. 8. Transmission electron microscope photographs of the wear debris particles collected from the test at $600^{\circ} \mathrm{C}$ in vacuum.

but not by XRD (Fig. 7). This difference suggests that the oxidation slightly occurs even in vacuum because of the rather low vacuum of only rotary pump level. It is also substantiated by the observations of amorphous surface region by TEM.

$\mathrm{SiC}$ is normally very brittle and plastic deformation of $\mathrm{SiC}$ is restricted. Microstructural features also suggest that microfracture is the most probable mechanism for material removal even at high temperatures. It is reasonable to consider that oxidation promotes material removal because the wear loss in air was generally higher than that in vacuum as shown in Fig. 4. Since oxidation becomes more profound at high temperatures, the increase in the wear loss at high temperatures is also attributed to oxidation effects. Oxidation of $\mathrm{SiC}$ ceramics is usually evident at temperatures above $900^{\circ} \mathrm{C}$ in air, forming a dense oxide product which protects $\mathrm{SiC}$ from further oxidation. Since frictional contact provides additional heat, oxidation could be observed even in the wear surfaces tested at room temperature. ${ }^{24)}$ Furthermore, repetitive contact would readily remove the protective oxide film which usually forms on the $\mathrm{SiC}$ bullk surface in case of static oxidation.

Woydt and Habig, ${ }^{6)}$ and Wang et al. ${ }^{8)}$ consistently suggested that oxidation could promote material removal because oxidation product, that is $\mathrm{SiO}_{2}$, would be much softer than the original $\mathrm{SiC}$ material. However, detailed analyses in this study reveal that debris particles consist of $\mathrm{SiC}$ core and $\mathrm{SiO}_{2}$ coatings. This implies that the oxidation occurred after debris generation rather than that the material removal took place following to the initial oxidation of the bulk surface. On the other hand, it has been reported that the presence of oxygen could cause grain boundary oxidation. ${ }^{25)}$ If so, then it may accelerate the intergranular crack growth of $\mathrm{SiC}$ at high temperatures, resulting in an in- 

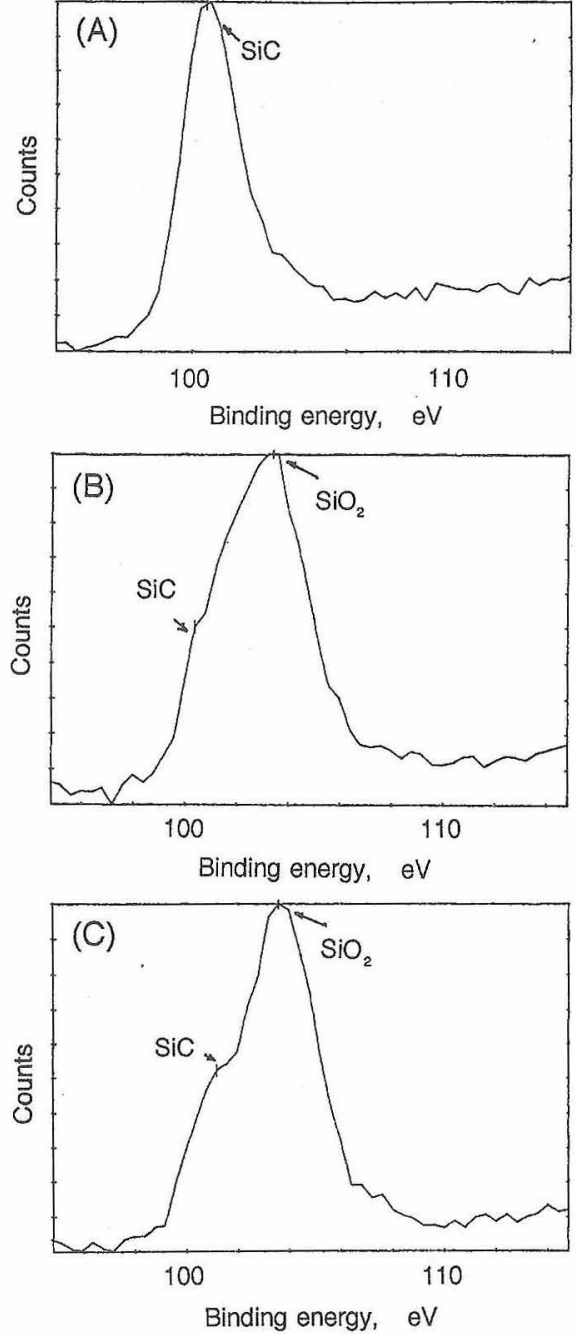

Fig. 9. X-ray photoelectron spectroscopy of SiC: (A) bulk surface before the wear test, (B) debris particles at $600^{\circ} \mathrm{C}$ in air, and (C) debris particles at $600^{\circ} \mathrm{C}$ in vacuum.

crease in the wear loss by intergranular microfracture. This effect seems more critical to the increase in the wear loss at elevated temperatures.

In contrast, under a contact pressure of $0.2 \mathrm{MPa}$, a significant decrease in wear loss was observed at the highest temperature, against the general tendency that the wear loss increases with an increase of temperature. SEM observations revealed that a thick layer containing very fine particles consistently formed on the wear surfaces. Figure 10 shows elemental concentration maps by EPMA of the cross section of the wear surface under $0.2 \mathrm{MPa}$ at $1000^{\circ} \mathrm{C}$ in vacuum. Oxygen was substantially concentrated in the surface layer.

Similar wear loss decrease associated with a surface layer formation has been reported for alumina and mullite ceramics. 23),26)-28) It has been concluded that plastic deformation accompanied by dynamic recrystallization during the sliding wear forms the fine-grain-size surface layer and that it acts as solid lubrication layer due to its low deformation resistance. ${ }^{23), 29)}$ The surface layer of $\mathrm{SiC}$ however contains substantial amount of oxygen suggesting that the layer consists of partially oxidized wear debris instead of recrystallized fine grains. Regardless of the formation mechanism, a layer of fine-grain-size particles could have low deformation resistance by grain boundary slide or rotation mechanisms. Soft $\mathrm{SiO}_{2}$ coating of the particle may en-

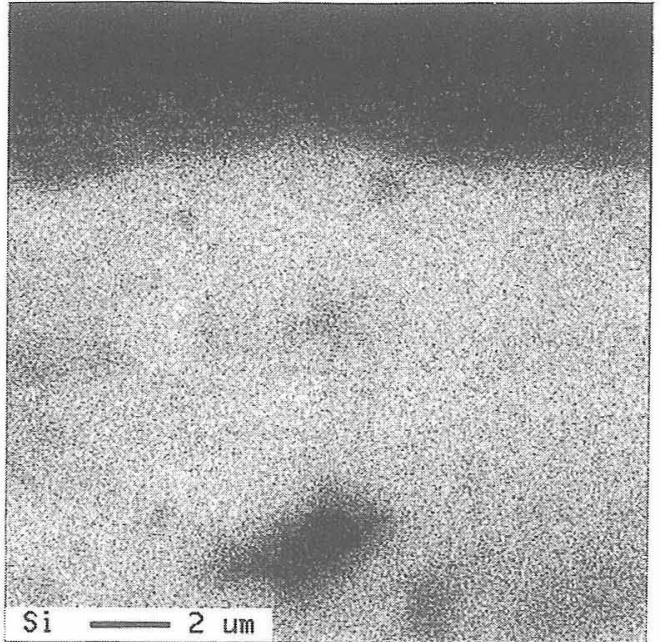

(A)

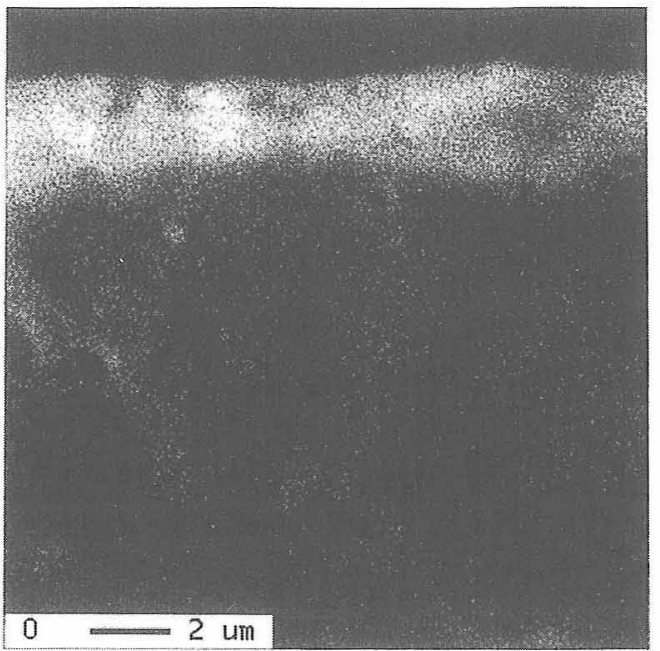

(B)

Fig. 10. Electron-probe microanalysis of the cross section of the wear surface region at $1000^{\circ} \mathrm{C}$ in vacuum: (A) silicon and (B) oxygen. In the top layer, $\mathrm{O}$ is richer but $\mathrm{Si}$ is less rich.

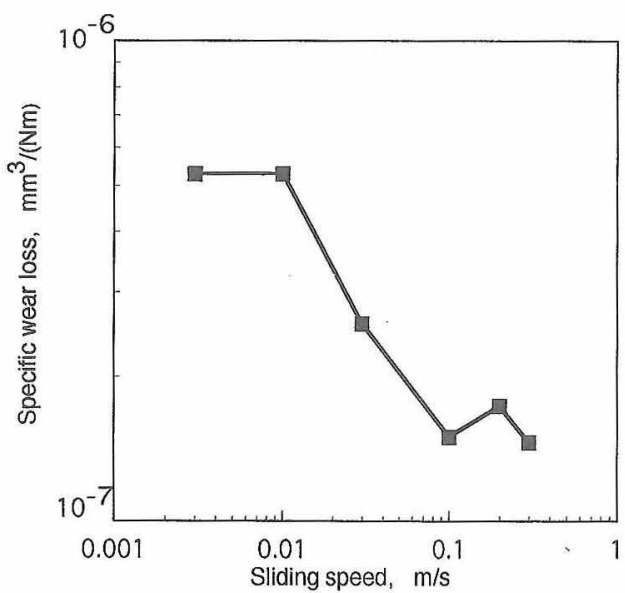

Fig. 11. Effect of sliding speed on specific wear loss of $\mathrm{SiC}$ at $1000^{\circ} \mathrm{C}$ in air under a contact pressure of $0.4 \mathrm{MPa}$.

hance the deformability. If a soft layer stays on the hard substrate, wear can be reduced by a solid lubrication effect of the layer. For higher contact pressure case, this type of layer could not be formed stably because such layer was easily 
removed away from the wear surface resulting in a higher wear loss.

Figure 11 depicts the effect of sliding speed on the wear loss of $\mathrm{SiC}$ at $1000^{\circ} \mathrm{C}$ in air. The specific wear loss simply decreased with an increase of sliding speed. At higher sliding speed tests, a thick layer of fine-grain-size particles were observed at the wear surface. It is not clear whether this was directly related to the effect of sliding speed itself or that of temperature because local surface temperature also depends on the sliding speed. Although the sliding conditions required for this low wear mode are not well defined, lower contact pressure (or applied load) and higher sliding speed are the preferable conditions for contact with low wear loss at high temperatures.

\section{Conclusions}

Friction and wear tests of a sintered $\mathrm{SiC}$ ceramic were conducted from room temperature to $1200^{\circ} \mathrm{C}$. Effects of temperature, atmosphere and test parameters on the tribological characteristics of $\mathrm{SiC}$ were investigated. The coefficient of friction was not much dependent on temperature, especially under a higher contact pressure. The coefficient of friction in air was larger than that in vacuum. Specific wear loss generally increased with an increase of temperature, and was higher in air than in vacuum. Partial oxidation was evident at $600^{\circ} \mathrm{C}$ and above from the detailed analyses of wear debris. These results suggest that oxidation generally accelerates intergranular microcracking and increases the wear loss. However, there could be a particular case that the wear loss significantly decreases when the contact pressure is low and the sliding speed is high, where thick surface layer of oxide-containing particles is formed.

Acknowledgments This study was conducted during the stay of one of the authors (H. X.) at the Ship Research Institute. The stay was supported by STA Fellowship Program. The authors express special appreciation to Prof. J. Drennan at University of Queensland for reviewing the manuscript, Dr. L. Chen at Tohoku University for TEM observations, Mr. D. Wang at Central South University of Technology of China for XPS analyses, and Mr. N. Kotani at Ship Research Institute for EPMA.

\section{References}

1) S. Jahanmir, Mater. Res. Soc. Symp. Proc., 140, 285-91 (1989).

2) H. Knoch and M. Fundus, Ceramic Technology International, 1995, 59-63 (1995).

3) B. Longson, Tribol. Int., 16, 221-25 (1983).

4) C. S. Yust and F. J. Carignan, ASLE Trans., 28, 245-52 (1985).

5) P. Boch, F. Platon and G. Kapelski, "Proc. of EUROTRIB 89 Espoo," Vol. 3 (1989) pp. 114-19.
6) M. Woydt and K. H. Habig, Tribol. Int., 22, 75-88 (1989).

7) M. G. Gee, C. S. Matharu, E. A. Almond and T. S. Eyre, "Wear of Materials 1989," Ed. by K. C. Ludema, American Society of Mechanical Engineers (1989) pp. 387-98.

8) H. Wang, Y. Kimura and K. Okada, "Proc. of the Japan International Tribology Conference Nagoya 1990," Japanese Society of Tribologists, Tokyo (1990) pp. 1389-94.

9) H. Mizutani, Y. Shimura, Y. Yahagi and S. Hotta, "Proc. of the Japan International Tribology Conference Nagoya 1990," Japanese Society of Tribologists (1990) pp. 1461-66.

10) X. Dong, S. Jahanmir and L. K. Ives, Tribol. Int., 28, 559-72 (1995).

11) O. O. Adewoye and T. F. Page, Wear, 70, 37-51 (1981).

12) M. Takatsu, H. Kamiya, K. Kubota and K. Seki, J. Ceram. Soc. Japan, 98, 964-70 (1990).

13) A. Blomberg, M. Olsson, J. Bratthäll, H. Engström and S. Hogmark, "Proc. of the Japan International Tribology Conference Nagoya 1990," Japanese Society of Tribologists (1990) pp. 1371-76.

14) S. Hogmark, M. Olsson and A. Blomberg, J. Hard Mater., 3, 153-67 (1992).

15) A. Blomberg, M. Olsson and S. Hogmark, Wear, 171, 77-89 (1994).

16) S. M. Hsu, M. C. Shen, T. N. Ying, Y. S. Wang and S.W. Lee, "Proc. 5th Inter. Symp. on Ceramic Materials and Components for Engines," Ed. by D. S. Yan, X. R. Fu and S. X. Shi, World Scientific (1995) pp. 111-27.

17) J.-M. Martin, T. LeMogne and M. N. Gardos, "Proc. of the Japan International Tribology Conference Nagoya 1990," Japanese Society of Tribologists (1990) pp. 1407-12.

18) S. Kitaoka, T. Tsuji, T. Katoh, Y. Yamaguchi and K. Kashiwagi, J. Am. Ceram. Soc., 77, 1851-56 (1994).

19) S.-J. Cho, C.-D. Um and S.-S. Kim, J. Am. Ceram. Soc., 78, 1076-78 (1995)

20) K. Miyoshi and D. H. Buckley, "Tribology of Ceramics," Vol. I, Ed. by S. Jahanmir, Society of Tribologists and Lubrication Engineers (1987) pp. 146-56.

21) K. Miyoshi, D. H. Buckley and M. Srinivasan, Am. Ceram. Soc. Bull., 62, 494-500 (1983).

22) T. Senda, C. Iino, S. Uematsu and S. Amada, Trans. Jpn. Soc. Mech. Engr., 57C, 2422-27 (1991).

23) T. Senda, J. Drennan and R. McPherson, J. Am. Ceram. Soc., 78, 3018-24 (1995).

24) T. Senda, Y. Yamamoto and Y. Ochi, J. Ceram. Soc. Japan, 101, 461-65 (1993).

25) E. Minford, J. A. Costello, I. S. T. Tsong and R. E. Tressler, "Fracture Mechanism of Ceramics," Vol. 5, Ed. by D.A. Rigney, Plenum Press (1982) pp. 511-22.

26) T. Senda, M. Saruta and Y. Ochi, J. Ceram. Soc. Japan, 102, 556-61 (1994).

27) X. Dong, S. Jahanmir and S. M. Hsu, J. Am. Ceram. Soc., 74, 1036-44 (1991).

28) K. Adachi, K. Kato, E. Inoue and Y. Kagimoto, Trans. Jpn. Soc. Mech. Engr., 61C, 2553-58 (1995).

29) H. Xiao, T. Senda and E. Yasuda, J. Am. Ceram. Soc., 79, 3243-49 (1996) 